\title{
Multimodal Investigation of Neuroinflammation in Aviremic Patients With HIV on Antiretroviral Therapy and HIV Elite Controllers
}

Hasan Sari, PhD,* Riccardo Galbusera, PhD,* Guillaume Bonnier, PhD, Yang Lin, MS, Zeynab Alshelh, PhD, Angel Torrado-Carvajal, PhD, Shibani S. Mukerji, MD, PhD, Eva M. Ratai, PhD, Rajesh T. Gandhi, MD, Jacqueline T. Chu, PhD, Oluwaseun Akeju, MD, Vwaire Orhurhu, PhD, Andrew N. Salvatore, MS, Janet Sherman, PhD, Douglas S. Kwon, MD, PhD, Bruce Walker, MD, Bruce Rosen, MD, PhD, Julie C. Price, PhD, Lauren E. Pollak, PhD, Marco L. Loggia, PhD, † and Cristina Granziera, MD, PhD $†$

Neurol Neuroimmunol Neuroinflamm 2022;9:e1144. doi:10.1212/NXI.0000000000001144

\section{Abstract}

\section{Background and Objectives}

The presence of HIV in the CNS has been related to chronic immune activation and cognitive dysfunction. The aim of this work was to investigate (1) the presence of neuroinflammation in aviremic people with HIV (PWH) on therapy and in nontreated aviremic PWH (elite controllers [ECs]) using a translocator protein $18 \mathrm{kDa}$ radioligand; (2) the relationship between neuroinflammation and cognitive function in aviremic $\mathrm{PWH}$; and (3) the relationship between $\left[{ }^{11} \mathrm{C}\right]$-PBR28 signal and quantitative MRI (qMRI) measures of brain tissue integrity such as T1 and $\mathrm{T} 2$ relaxation times ( $\mathrm{rts}$ ).

\section{Methods}

$\left[{ }^{11} \mathrm{C}\right]$-PBR28 (standard uptake value ratio, SUVR) images were generated in 36 participants (14 PWH, 6 ECs, and 16 healthy controls) using a statistically defined pseudoreference region. Group comparisons of $\left[{ }^{11} \mathrm{C}\right]$-PBR28 SUVR were performed using region of interest-based and voxelwise analyses. The relationship between inflammation, qMRI measures, and cognitive function was studied.

\section{Results}

In region of interest analyses, ECs exhibited significantly lower $\left[{ }^{11} \mathrm{C}\right]-\mathrm{PBR} 28$ signal in the thalamus, putamen, superior temporal gyrus, prefrontal cortex, and cerebellum compared with the PWH. In voxelwise analyses, differences were observed in the thalamus, precuneus cortex, inferior temporal gyrus, occipital cortex, cerebellum, and white matter (WM). $\left[{ }^{11} \mathrm{C}\right]-\mathrm{PBR} 28$ signal in the WM and superior temporal gyrus was related to processing speed and selective attention in PWH. In a subset of PWH $(n=12),\left[{ }^{11} \mathrm{C}\right]-\mathrm{PBR} 28$ signal in the thalamus and WM regions was related to a decrease in $\mathrm{T} 2 \mathrm{rt}$ and to an increase in $\mathrm{T} 1 \mathrm{rt}$ suggesting a colocalization of increased glial metabolism, decrease in microstructural integrity, and iron accumulation.

\section{Discussion}

This study casts a new light onto the role of neuroinflammation and related microstructural alterations of HIV infection in the CNS and shows that ECs suppress neuroinflammation more effectively than $\mathrm{PWH}$ on therapy.
Correspondence

Dr. Granziera

cristina.granziera@usb.ch

\section{RELATED ARTICLE}

Editorial

Is HIV Brain Disease

Preventable?

Page e 1145

*These authors contributed equally to this work as co-first authors.

tThese authors contributed equally to this work as co-last authors.

From the MGH/MIT/HMS Athinoula A. Martinos Center for Biomedical Imaging (H.S., Y.L., Z.A., A.T.-C., E.M.R., A.N.S., B.R., J.C.P., M.L.L.), Massachusetts General Hospital, Harvard Medical School, Charlestown; Neurologic Clinic and Policlinic (R.G., G.B., C.G.), Departments of Medicine, Clinical Research and Biomedical Engineering, University Hospital Basel and University of Basel, Switzerland; Translational Imaging in Neurology (ThINk) Basel (R.G., G.B., C.G.), Department of Biomedical Engineering, University Hospital Basel and University of Basel, Switzerland; Medical Image Analysis and Biometry Lab (A.T.-C.), Universidad Rey Juan Carlos, Madrid, Spain; Department of Neurology (S.S.M., R.T.G.), Infectious Diseases (J.T.C.), Department of Anesthesia (O.A., V.O.), and Department of Psychiatry (J.S., L.E.P.), Massachusetts General Hospital, Boston; and Ragon Institute of MGH (D.S.K., B.W.), MIT and Harvard, Cambridge, MA.

Go to Neurology.org/NN for full disclosures. Funding information is provided at the end of the article. 


\section{Glossary}

ANOVA = analysis of variance cART $=$ combined antiretroviral therapy; $\mathbf{E C}=$ elite controller; FoV $=$ field of view; $\mathbf{H A B}=$ high-affinity binder; HAND = HIV-associated neurocognitive disorder; HC = healthy control; MAB = mixed-affinity binder; MEMPRAGE = multi-echo magnetization-prepared rapid gradient echo; NTBI = non-transferrin-bound iron; PWH = people with HIV; qMRI = quantitative MRI; ROI = region of interest; $\mathbf{r t}$ = relaxation time; SIV = simian immunodeficiency virus; SUV $=$ standardized uptake value; SUVR $=$ SUV ratio; TE $=$ echo time; $T$ MT $=$ Trail Making Test TR $=$ repetition time; TSPO $=$ translocator protein $18 \mathrm{kDa}$; $\mathbf{W M}=$ white matter.

The prognosis of HIV infection has dramatically improved in the combined antiretroviral therapy (cART) era. ${ }^{1}$ Nevertheless, HIV-infected patients have the persistence of the virus in specific body reservoirs (sanctuaries) and in resting memory CD4 T cells, despite optimal treatment and undetectable blood viral load. ${ }^{2}$ One of those HIV sanctuaries is the CNS, where the virus penetrates within a week from primum infection ${ }^{3}$ and then persists within macrophages, astrocytes, and microglia, ${ }^{4}$ hereby triggering chronic neuroinflammation. Persistent lowgrade inflammation within the brain of people with HIV (PWH) has been related to the development of HIV-associated neurocognitive disorders (HANDs), which affect nearly half of the patients who achieved viral suppression on therapy. ${ }^{5}$

Elite controllers (ECs) represent a very rare group of individuals with the ability to maintain an undetectable HIV-1 RNA overtime in the absence of cART. ${ }^{6}$ The mechanisms underlying virologic control in ECs remain unknown, but it has been shown that some of them achieve asymptomatic HIV-1 infection and prolonged control of clinical progression without cART. ${ }^{7}$ ECs harbor HIV reservoirs in some body parts (i.e., small bowel, lymphoid areas, and male reproductive tract) as it was shown in an antibody-targeted PET study in a simian immunodeficiency virus (SIV) model. ${ }^{8}$ Nevertheless, whether a brain HIV reservoir exists in ECs is to date unknown.

Several neuroimaging methods permit the investigation of the mechanisms underlying neuroinflammatory processes and the consequences of CNS inflammation in living patients. Radiotracers for PET that bind to the translocator protein $18 \mathrm{kDa}$ (TSPO) have proven to be sensitive to inflammatory processes in neurologic disorders involving glial cells. ${ }^{9,10}$ TSPO is a protein located in the outer mitochondrial membrane of microglia and, to a lesser extent, astrocytes, which is thought to play a role in immune response, steroid synthesis, and apoptosis. TSPO expression in the normal brain parenchyma is thought to be low, but in the event of glial activation or macrophage infiltration, a rise in the TSPO expression has been repeatedly observed. ${ }^{11,12}$ Using a second-generation TSPO tracer, i.e., $\left[{ }^{11} \mathrm{C}\right]-\mathrm{PBR} 28$, a significant TSPO signal increase has been observed in several conditions, such as chronic pain, multiple sclerosis, amyotrophic lateral sclerosis, and others. ${ }^{13-17}$ Most relevant for the current study, an increased uptake of $\left[{ }^{11} \mathrm{C}\right]-\mathrm{PBR} 28$ in parietal and occipital lobes and in the globus pallidus were reported in asymptomatic $\mathrm{PWH}$ on therapy compared to healthy controls (HCs). ${ }^{18}$
In this study, we aimed at investigating whether the rare ECs exhibit neuroinflammation to the same extent as $\mathrm{PWH}$ on cART and whether neuroinflammation has a functional cognitive correlate. Furthermore, we took advantage of the integrated PET/MRI to explore the relationship between the molecular-level signals provided by $\left[{ }^{11} \mathrm{C}\right]-\mathrm{PBR} 28$ and the microstructural tissue changes in areas of neuroinflammation in patients with HIV. In fact, quantitative MRI (qMRI) such as T1 and $\mathrm{T} 2$ relaxometry provides a measure of tissue-level microstructural properties and hereby helps to reveal the structural correlates of neuroinflammation, such as edema, demyelination, tissue degeneration, and iron accumulation. ${ }^{19,20}$ Our hypothesis was that the combination of neuroinflammatory and microstructural information may provide a more complete insight into the pathophysiology of HIV infection of the CNS.

\section{Methods}

\section{Population and Data Acquisition}

We enrolled PWH and ECs who had been on stable aviremia (viral load $<50$ copies $/ \mathrm{mL}$ ) for at least 1 year and on cART for at least 6 months (PWH) and HCs which were identified from a subject pool with no history of neurologic and psychiatric condition. Subjects were scanned using a Siemens PET/MRI scanner consisting of a dedicated brain avalanche photodiodebased PET scanner operating in the bore of a $3 \mathrm{~T}$ TRIO magnetic resonance scanner equipped with an 8-channel head coil.

PET data were acquired for 90 minutes after injection of inhouse produced $\left[{ }^{11} \mathrm{C}\right]-\mathrm{PBR} 28$. PET data from 60 to $90 \mathrm{mi}-$ nutes postinjection were reconstructed into six 5 -minute time frames using OP-OSEM reconstruction. Corrections for attenuation $^{21}$ and motion ${ }^{22}$ were applied, and PET images were reconstructed to a voxel size of $1.4 \times 1.4 \times 2 \mathrm{~mm}^{3}$. T1weighted multi-echo magnetization-prepared rapid gradient echo (MEMPRAGE) images (repetition time [TR]/echo time $[\mathrm{TE}]=2,530 / 1.64$ milliseconds; voxel size $=1 \times 1 \times$ $1 \mathrm{~mm}^{3}$ ) were also acquired for these subjects.

For a subset of PWH (age: $57 \pm 5$ years; sex: 11 men and 2 women), additional MR data were acquired using a protocol consisting of (1) magnetization-prepared 2 rapid acquisition gradient echoes $(\mathrm{TR} / \mathrm{TE}=5,000 / 2.89$ milliseconds, voxel size $=1.0 \times 1.0 \times 1.2 \mathrm{~mm}^{3}$, field of view $[\mathrm{FoV}]=256 \times 240 \times$ 212 , and acquisition time $=8: 22$ minutes) for T1 relaxometry 
and (2) T2 relaxometry sequence $(\mathrm{TR} / \mathrm{TE}=5,850 / 9$ milliseconds, 21 echos, 20 slices: voxel size $=1.0 \times 1.0 \times 4.0 \mathrm{~mm}^{3}$, $\mathrm{FoV}=210 \times 175 \times 120$, and acquisition time $=3$ minutes), which uses a new nonlinear inverse reconstruction algorithm that directly estimates a T2 map. ${ }^{23}$ One of these 13 subjects was excluded from the analysis due to motion artifacts in $\mathrm{T} 1$ and $\mathrm{T} 2$ relaxometry data. Among the remaining 12 subjects, 4 were mixed-affinity binders (MABs) ( 3 men and 1 woman), and 8 were high-affinity binders (HABs) $(7$ men and 1 woman). The characteristics of subject population and image protocols are summarized in eTable 1 (links.lww.com/NXI/ A692).

\section{PET Image Processing}

Average images of the reconstructed PET data (60-90 minutes postinjection) were computed, and standardized uptake value (SUV) maps (i.e., mean radioactivity/injected dose/ weight) were generated using in-house software (MATLAB v2019; MathWorks, Natick, MA). SUV images were registered to MEMPRAGE space using FSL software. ${ }^{24}$ SUV maps were spatially smoothed $(4 \mathrm{~mm})$ to improve the signal-tonoise ratio.

Next, coregistered PET/MR images were transformed to Montreal Institute space using FSL $^{24}$ where the regions of interest (ROIs), which were selected based on previous literature, ${ }^{18}$ were defined using the Harvard-Oxford atlas. ${ }^{25}$ These anatomically defined ROIs were the following: thalamus, putamen, amygdala, hippocampus, parietal operculum cortex, superior temporal, white matter (WM), and brainstem.

To reduce the global PET signal variability across subjects, we computed SUV ratio (SUVR) maps. SUVR has been used in several $\left[{ }^{11} \mathrm{C}\right]-\mathrm{PBR} 28$ studies and demonstrates good ability to detect signal elevations in regions where neuroinflammation is known or expect to occur (e.g., motor cortex in amyotrophic lateral sclerosis) basal ganglia in Huntington disease, ${ }^{17,26}$ and good concordance with indices of specific binding determined using PET pharmacokinetic modeling methods (e.g., volume of distribution ratio). ${ }^{27,28}$

Because of the lack of a true reference region devoid of TSPO, a statistically defined pseudoreference region was used in this normalization based on the absence of statistically significant SUV differences between groups, as previously described by Albrecht et al. ${ }^{29}$ Whole-brain voxelwise group comparisons of SUVs were conducted covarying for age, sex, and TSPO genotype. The resultant $z$-maps were thresholded to include voxels between -0.2 and $0.2(p>0.84)$ (i.e., only voxel not statistically different across groups). ${ }^{29}$ The resulting region was used as a pseudoreference region to normalize SUV values from ROIs.

\section{MRI Processing}

The MRI analysis was performed on the central part of the brain, roughly $40 \mathrm{~mm}$ below and above the thalamus, because the $\mathrm{T} 2$ relaxation time (rt) maps were only acquired in that region due to their long acquisition time. Therefore, we focused our analysis on the WM area and thalamus, 2 regions with elevated uptake of $\left[{ }^{11} \mathrm{C}\right]-\mathrm{PBR} 28$ in our cohort of patients compared with controls (see Results). The tissue concentration was estimated using an in-house algorithm by excluding voxels with more than $1 \%$ CSF to minimize partial volume effects. ${ }^{30}$

\section{Cognitive Tests}

Twelve PWH and 5 ECs also agreed to be administered 2 standardized cognitive tests, the Trail Making Test (TMT), Parts $\mathrm{A}$ and $\mathrm{B},{ }^{31}$ and the Stroop Color and Word Test. ${ }^{32}$ These tests evaluate the integrity of various executive functioning skills, including visuomotor speed (TMT-A), set switching (TMT-B), and both response rates and response inhibition (as indicated by the derived interference scores') on the Stroop Color and Word Test. The participants' raw scores on each of these tests were converted to $z$-scores using agematched normative data. ${ }^{32,33}$

\section{Statistical Analysis}

Group comparisons of $\left[{ }^{11} \mathrm{C}\right]$-PBR28 SUVR were performed in ROI analyses, using either (1) anatomically defined or (2) contrast-defined ROIs (see below), and (3) in the whole brain voxelwise.

For the 8 anatomically defined ROIs, the mean PET signal was compared across groups ( $\mathrm{PWH}, \mathrm{ECs}$, and $\mathrm{HCs}$ ) using analysis of variance (ANOVA), with TSPO genotype sex, and age as covariates. Bonferroni correction was used to correct for the number of regional comparisons. For the regions with a statistically significant group effect, the Dunnett post hoc test was used to evaluate whether ECs were different from HCs and PWHs.

In addition to a priori anatomically defined ROIs, group comparisons were also performed using regions identified in a voxelwise ANOVA, testing for group differences between $\mathrm{HCs}$, ECs, and PWH $\left[{ }^{11} \mathrm{C}\right]-\mathrm{PBR} 28$ SUVR maps using nonparametric permutation inference implemented on FSL. ${ }^{24}$ The resulting $Z$ statistic image was postprocessed using a clusterforming threshold of $Z=3.1$ (main analyses) or $Z=2.3$ (a more liberal threshold for exploratory purposes) and a cluster size significance threshold of $p=0.05$. The resultant map was masked with regions from Harvard-Oxford atlas ${ }^{25}$ resulting in contrast-defined ROIs. From these regions, the mean $\left[{ }^{11} \mathrm{C}\right]$ PBR28 SUVR was extracted, and a Dunnett post hoc test was used to test for differences between ECs and HCs or PWH.

In addition to these ROI-based analyses, direct contrasts were computed between (1) ECs and PWH or (2) ECs and HCs by using a whole-brain voxelwise general linear model, correcting for TSPO genotype, sex, and age. As for the abovementioned voxelwise ANOVA contrast, direct contrasts were cluster corrected using cluster-forming thresholds of $Z=2.3$ and $Z=3.1$ and a cluster size significance threshold of $p=0.05$. 
For all regions with a significant group difference in anatomically defined and contrast-defined ROIs, the association between $\left[{ }^{11} \mathrm{C}\right]$-PBR28 SUVR and cognitive test scores was evaluated using partial correlation controlling for sex, age, education, and genotype. Cognitive scores were also correlated with MR T1 and T2 rt values.

Based on a general assumption of monotonic relationship between $\left[{ }^{11} \mathrm{C}\right]$-PBR28 SUVR and T1/T2 rt, we estimated for each subject the correlation between the thalamus and WM by using the Spearman correlation test. Furthermore, a correlation analysis was run comparing the mean $\left[{ }^{11} \mathrm{C}\right]-\mathrm{PBR} 28$ SUVR, T1, and T2 values in the thalamus and WM using the same covariates. All statistical tests were performed using MATLAB (v 2019a; MathWorks) and SPSS (v15; IBM Corp., Armonk, NY) software packages.

\section{Standard Protocol Approvals, Registrations, and Patient Consents}

All subjects gave written informed consent, and the study was approved by the local institutional review board committee.

\section{Data Availability}

Data presented in this work can be shared by the corresponding author to qualified investigators on request.

\section{Results}

Fourteen PWH (age: $56 \pm 6$ years; sex: 13 men/ 1 woman; genotype: $10 \mathrm{HABs} / 4 \mathrm{MABs}$, as determined based on the Ala147Thr polymorphism in the TSPO gene), 16 HCs (age: $51 \pm 12$ years; sex: 10 men/ 6 women; genotype: $11 \mathrm{HABs} / 5$ MABs), and 6 ECs (age: $59 \pm 7$ years; sex: 5 men/ 1 woman; genotype: $4 \mathrm{HABs} / 2 \mathrm{MABs}$ ) were enrolled in the study (eTable 1, links.lww.com/NXI/A692). PWH CD4 cell count at the time of the PET-MRI scan did not differ from that of ECs (PWH: $708 \pm 260$, ECs: $692 \pm 188, p=0.90)$.

\section{Data-Driven Pseudoreference Region}

Voxels from the pseudoreference region used to normalize the cortical regions are shown in Figure 1A. This pseudoreference region identified encompassed portions of the lingual gyrus, cerebellum, temporal pole, and occipital lobes. Figure 1B shows that the SUV values within this region for HCs, ECs, and $\mathrm{PWH}$ were not statistically different.

\section{Anatomically Defined ROI Analyses}

Regional [ $\left.{ }^{11} \mathrm{C}\right]-\mathrm{PBR} 28$ SUVR values for HCs, ECs, and PWH for anatomically defined regions are shown in Table 1. After Bonferroni correction, results of the ANOVA test showed a significant group effect in $\left[{ }^{11} \mathrm{C}\right]-\mathrm{PBR} 28$ SUVR in 7 of the 8 considered ROIs (thalamus, putamen, brainstem, and parietal

Figure 1 PET Signal in the Pseudoreference Region and Normalized SUVR Values in Target ROIs

A
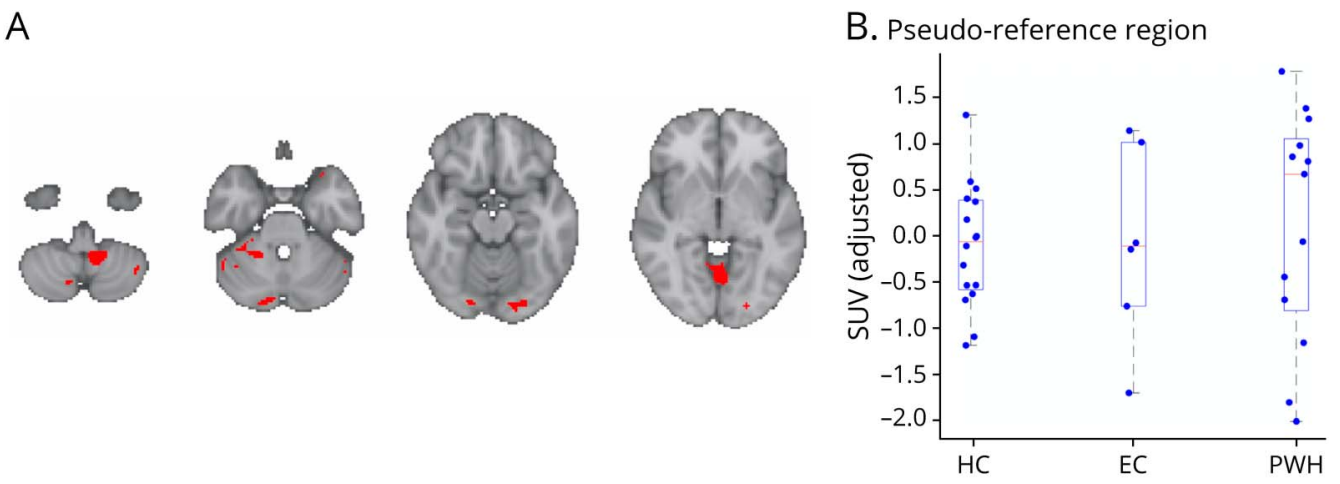

C.a Thalamus

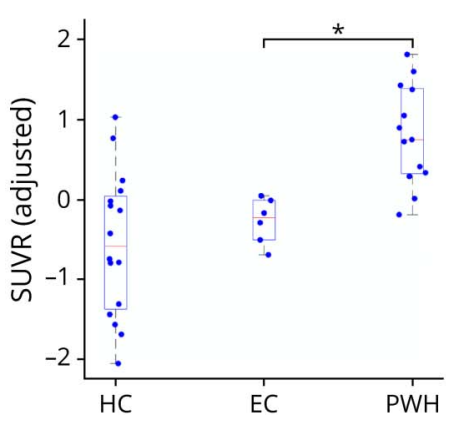

C.b Parietal operculum cortex

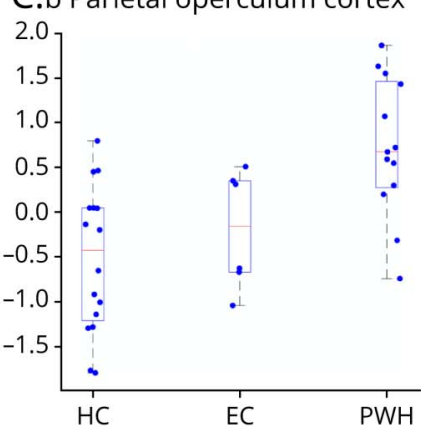

C.c White matter

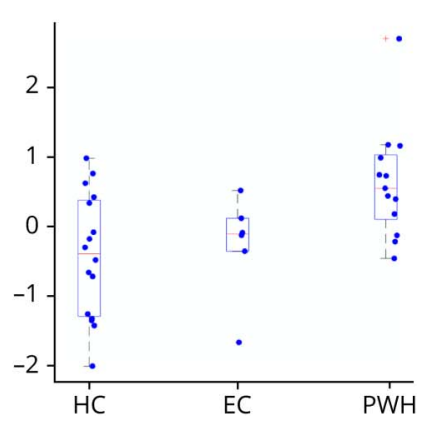

Statistically obtained pseudoreference region used to normalize PET images to obtain SUVR values (A). SUV values, adjusted for age, sex, and genotype, within this pseudoreference region in $\mathrm{HCS}$, ECs, and $\mathrm{PWH}(\mathrm{B})$, boxplots of $\left[{ }^{11} \mathrm{C}\right]$-PBR28 SUVR values, adjusted for age, sex, and genotype, extracted from anatomically defined ROIs (thalamus [C.a], parietal operculum cortex [C.b], and white matter [C.c]) in HCs, ECs, and PWH (C.a-C). *p < 0.05 (Dunnett test). EC = elite controller; $\mathrm{HC}=$ healthy control; $\mathrm{PWH}=$ people with $\mathrm{HIV} ; \mathrm{ROI}=$ region of interest; SUVR = standard uptake value ratio. 
operculum cortex $[p<0.01]$; superior temporal, amygdala, and WM $(p<0.05))$. Results of the Dunnett post hoc test, as shown in Table 1, revealed that ECs exhibit significantly lower $\left[{ }^{11} \mathrm{C}\right]$-PBR28 SUVR compared with the PWH in the thalamus $(p<0.05)$. No statistically significant group differences were seen between ECs and HCs in any of the regions. Figure 1C shows box plots of SUVR values for each group in the thalamus, parietal operculum cortex, and WM.

\section{Contrast-Based ROI Analysis}

Results of the ANOVA voxelwise contrast yielded a statistically significant group effect in $\left[{ }^{11} \mathrm{C}\right]$-PBR28 SUVR in the insula, precuneus, prefrontal cortex, medial frontal cortex, posterior parietal cortex, and cerebellum (Table 1; Figure 2A). Figure 2B shows the average $\left[{ }^{11} \mathrm{C}\right]$-PBR28 SUVR within several contrastdefined ROIs: prefrontal cortex, cerebellum, and occipital cortex for HCs, ECs, and PWH. Results of 2-sided Dunnett post hoc tests showed significantly lower $\left[{ }^{11} \mathrm{C}\right]-\mathrm{PBR} 28$ SUVR in ECs vs $\mathrm{PWH}$ in the prefrontal cortex and significantly higher $\left[{ }^{11} \mathrm{C}\right]$ PBR28 SUVR in ECs vs HCs in the cerebellum $(p<0.05)$.

\section{Voxelwise Analysis}

As shown in Figure 3A, voxelwise contrasts between ECs and $\mathrm{PWH}$ showed widespread regions of significantly lower $\left[{ }^{11} \mathrm{C}\right]$ PBR28 SUVR in the former group, including in the thalamus,
WT, precuneus cortex, putamen, middle and inferior temporal gyrus, occipital cortex, and cerebellum. No regions showed significant difference between ECs and HCs (Figure 3B).

\section{Association Between PET [ $\left.{ }^{11} \mathrm{C}\right]-\mathrm{PBR} 28$ Signal and $\mathrm{T} 1$ and $\mathrm{T} 2 \mathrm{rt}$ in the Thalamus and WM}

Average $\mathrm{T} 1$ and $\mathrm{T} 2 \mathrm{rt}$ values in the $\mathrm{WM}$ and thalamus were consistent with previous literature (WM: T1 $=1,095 \pm 32$ milliseconds, $\mathrm{T} 2=71 \pm 3$ milliseconds; thalamus: $\mathrm{T} 1=1,174$ \pm 36 milliseconds, $\mathrm{T} 2=81 \pm 1$ milliseconds). ${ }^{22-24}$ In the thalamus, no correlation was observed between $\mathrm{T} 1 \mathrm{rt}$ and $\left[{ }^{11} \mathrm{C}\right]$-PBR28 SUVR (average mean adj- $R=-0.01$ ) (Figure 4A). Spearman correlation between $\mathrm{T} 2 \mathrm{rt}$ and $\left[{ }^{11} \mathrm{C}\right]$ PBR28 SUVR in the thalamus showed a negative correlation in all subjects (average mean adj- $R=-0.33$ ) (Figure 4B). In the WM, there was a weak direct correlation between $\mathrm{T} 1 \mathrm{rt}$ and $\left[{ }^{11} \mathrm{C}\right]$-PBR28 SUVR (average mean adj- $R=0.17$ ), whereas the indirect correlation between $\mathrm{T} 2 \mathrm{rt}$ and $\left[{ }^{11} \mathrm{C}\right]$ PBR28 SUVR in the WM was stronger (average mean adj$R=-0.41)$ (Figure 5).

\section{Association Between PET/MRI Results and Cognitive Test Scores}

Table 2 shows the cognitive raw scores for ECs and PWH (no cognitive scores are available for HCs as indicated above, the

Table 1 Regional ${ }^{11}$ C-PBR28 SUVR Values for HCs, ECs, and PWH for Anatomically Defined ROIs and Contrast-Based ROIs

\begin{tabular}{|c|c|c|c|c|c|c|c|c|}
\hline & \multirow{2}{*}{$\begin{array}{l}\text { HC MAB } \\
(n=5)\end{array}$} & \multirow{2}{*}{$\begin{array}{l}\text { HC HAB } \\
(n=11)\end{array}$} & \multirow{2}{*}{$\begin{array}{l}\text { EC MAB } \\
(n=2)\end{array}$} & \multirow{2}{*}{$\begin{array}{l}\text { EC HAB } \\
(n=4)\end{array}$} & \multirow{2}{*}{$\begin{array}{l}\text { PWH MAB } \\
(n=4)\end{array}$} & \multirow{2}{*}{$\begin{array}{l}\text { PWH HAB } \\
(n=10)\end{array}$} & \multicolumn{2}{|c|}{ Dunnett test $p$ values } \\
\hline & & & & & & & HC vs EC & PWH vs EC \\
\hline \multicolumn{9}{|l|}{ Anatomically defined ROIs } \\
\hline Thalamus & $0.94 \pm 0.13$ & $0.92 \pm 0.07$ & $0.92 \pm 0.04$ & $0.97 \pm 0.03$ & $1.03 \pm 0.05$ & $1.08 \pm 0.07$ & 0.30 & $0.02^{a}$ \\
\hline Putamen & $0.87 \pm 0.13$ & $0.84 \pm 0.08$ & $0.90 \pm 0.01$ & $0.90 \pm 0.07$ & $0.94 \pm 0.03$ & $1.02 \pm 0.08$ & 0.35 & 0.11 \\
\hline Amygdala & $0.95 \pm 0.16$ & $0.87 \pm 0.10$ & $0.93 \pm 0.05$ & $0.87 \pm 0.06$ & $0.98 \pm 0.09$ & $0.95 \pm 0.06$ & 0.58 & 0.39 \\
\hline Parietal operculum cortex & $0.85 \pm 0.10$ & $0.83 \pm 0.07$ & $0.85 \pm 0.06$ & $0.89 \pm 0.07$ & $0.90 \pm 0.04$ & $0.99 \pm 0.08$ & 0.34 & 0.07 \\
\hline Superior temporal & $0.87 \pm 0.13$ & $0.82 \pm 0.08$ & $0.87 \pm 0.11$ & $0.88 \pm 0.09$ & $0.94 \pm 0.07$ & $0.92 \pm 0.08$ & 0.25 & 0.77 \\
\hline White matter & $0.78 \pm 0.10$ & $0.74 \pm 0.06$ & $0.83 \pm 0.05$ & $0.75 \pm 0.07$ & $0.83 \pm 0.06$ & $0.84 \pm 0.07$ & 1.00 & 0.14 \\
\hline Medial frontal cortex & $1.00 \pm 0.11$ & $0.95 \pm 0.05$ & $1.07 \pm 0.00$ & $0.95 \pm 0.04$ & $1.11 \pm 0.10$ & $0.99 \pm 0.03$ & 1.00 & 0.95 \\
\hline \multicolumn{9}{|l|}{ Contrast-based ROIs } \\
\hline Insula & $0.90 \pm 0.13$ & $0.89 \pm 0.08$ & $0.90 \pm 0.05$ & $0.95 \pm 0.08$ & $0.94 \pm 0.05$ & $1.06 \pm 1.09$ & 0.25 & 0.09 \\
\hline Precuneus & $0.81 \pm 0.10$ & $0.83 \pm 0.07$ & $0.86 \pm 0.02$ & $0.91 \pm 0.09$ & $0.88 \pm 0.09$ & $0.97 \pm 0.07$ & 0.30 & 0.43 \\
\hline Occipital cortex & $0.95 \pm 0.08$ & $0.96 \pm 0.07$ & $0.98 \pm 0.01$ & $1.01 \pm 0.58$ & $1.07 \pm 0.12$ & $1.07 \pm 0.06$ & 0.27 & 0.12 \\
\hline Cerebellum & $0.97 \pm 0.03$ & $1.01 \pm 0.03$ & $1.01 \pm 0.08$ & $1.10 \pm 0.04$ & $1.14 \pm 0.06$ & $1.13 \pm 0.04$ & $0.04^{a}$ & 0.07 \\
\hline Prefrontal cortex & $0.87 \pm 0.14$ & $0.87 \pm 0.06$ & $0.93 \pm 0.06$ & $0.95 \pm 0.11$ & $0.97 \pm 0.09$ & $1.07 \pm 0.13$ & 0.07 & $0.04^{\mathrm{a}}$ \\
\hline Posterior parietal cortex & $0.84 \pm 0.12$ & $0.82 \pm 0.07$ & $0.86 \pm 0.01$ & $0.91 \pm 0.07$ & $0.92 \pm 0.11$ & $0.99 \pm 0.10$ & 0.21 & 0.18 \\
\hline Medial frontal cortex & $0.90 \pm 0.14$ & $0.89 \pm 0.07$ & $0.94 \pm 0.02$ & $0.97 \pm 0.11$ & $1.00 \pm 0.05$ & $1.09 \pm 0.13$ & 0.30 & 0.15 \\
\hline
\end{tabular}

Abbreviations: $A N O V A=$ analysis of variance; $E C=$ elite controller; $\mathrm{HAB}=$ high-affinity binder; $\mathrm{HC}=$ healthy control; $\mathrm{MAB}=$ mixed-affinity binder; $\mathrm{PWH}=$ people with $\mathrm{HIV} ; \mathrm{ROI}=$ region of interest; SUVR = standard uptake value ratio.

A 2-way ANOVA test with the Dunnett post hoc test was used to compute $p$ values between ECs and other groups using age, sex, and genotypes as covariates. ${ }^{a}$ Regions with significant group differences after Bonferroni correction. 
A

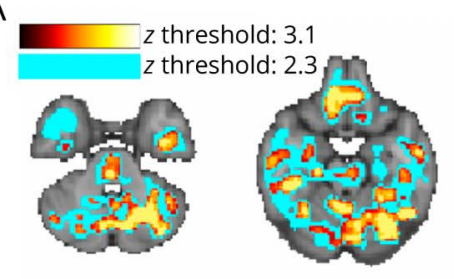

B.a Prefrontal cortex

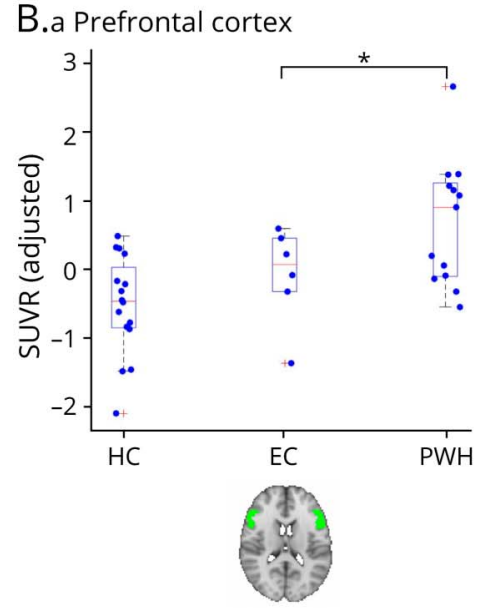

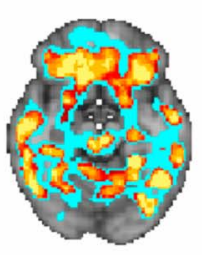

B.b Cerebellum
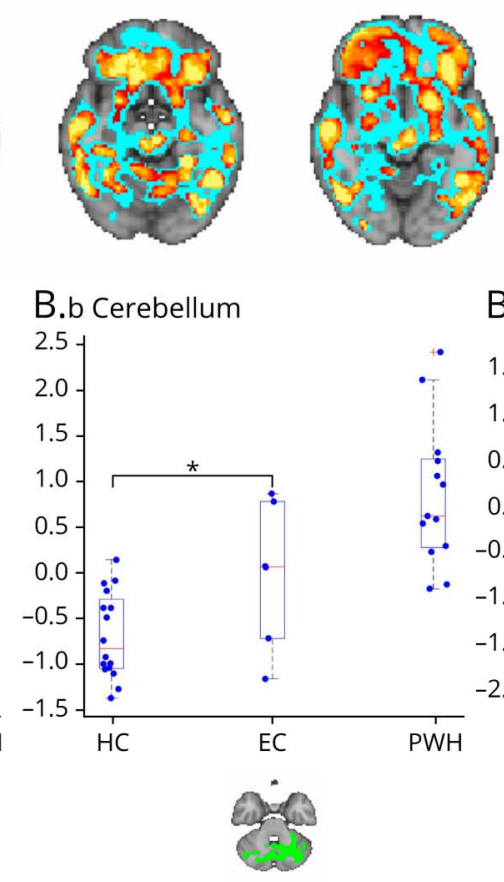

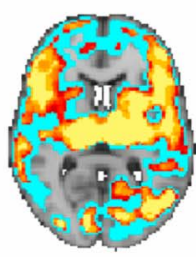

B.c Insula
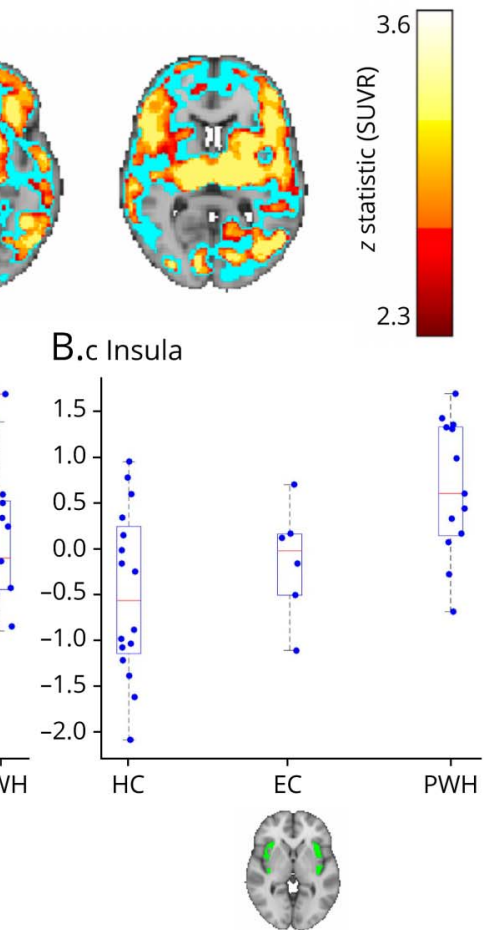

Whole-brain voxelwise ANOVA contrast, identifying regions with significantly different PET signal between groups (A). Voxels marked with cyan and red-yellow colors represent regions identified as statistically significant using a cluster-forming threshold of 2.3 and 3.1, respectively. Regions with significant difference (A) were intersected with labels from the Harvard-Oxford Structural Atlas, to identify contrast-defined ROIs. Mean SUVRs extracted from 3 of these regions (displayed in green): prefrontal cortex (B.a), cerebellum (B.b), and insula (B.c) ROIs (B.a-c). ${ }^{*} p<0.05$ (Dunnett test). ANOVA = analysis of variance; EC = elite controller; $\mathrm{HC}=$ healthy control; $\mathrm{PWH}=$ people with $\mathrm{HIV} ; \mathrm{ROI}=$ region of interest; SUVR = standard uptake value ratio.

tests used are standardized measures, and scores are based on comparison to age-matched normative data). No statistically significant difference was observed between groups for all of the test raw scores (unpaired $t$ test, $p>0.05$ ). PWH performed $<1.5 z$-score on the TMT-B test, whereas ECs performed $<1.5$ $z$-score on the Stroop Word Reading and Stroop Color Naming subtests (but not on the interference score).
In anatomic ROIs, a positive correlation was observed between the Stroop Color Naming and $\left[{ }^{11} \mathrm{C}\right]$-PBR28 signal in the WM $(r=0.56, p<0.05)$. A positive trend was seen between mean $\mathrm{T} 1$ rt in WM and Stroop Word Reading and Stroop Color-Word Test conditions $(r=0.67, p=0.05$ and $r=0.64, p=0.06$, respectively). No other significant relationship was observed between cognitive scores and $\left[{ }^{11} \mathrm{C}\right]-\mathrm{PBR} 28 \mathrm{SUVR}$ or T1/T2 rt.

Figure 3 Voxelwise Group Comparisons of [11C]-PBR28 PET Signal

A

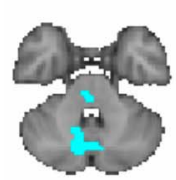

B

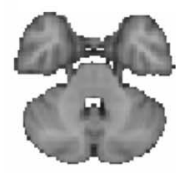

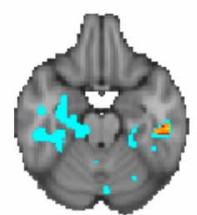

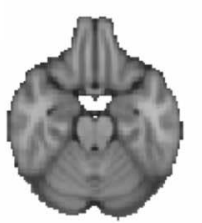

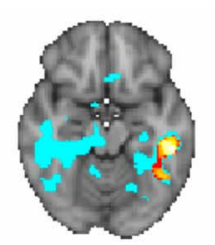

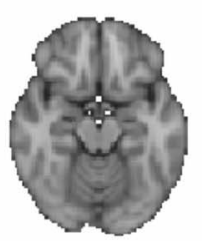

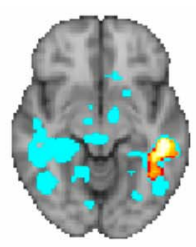

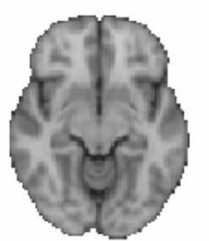

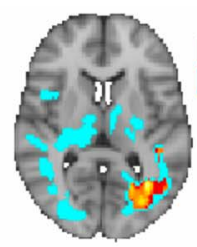

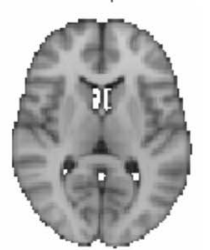

$z$ threshold: 3.1

$z$ threshold: 2.3

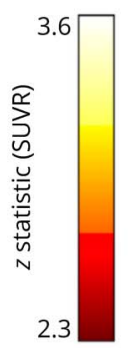

Results of voxelwise group comparison analysis between ECs and PWH (A) and between ECs and HCs (B). Voxels marked with cyan color and red-yellow colors represent regions identified as statistically significant using a cluster-forming threshold of 2.3 and 3.1 , respectively. $\mathrm{EC}=$ elite controller; $\mathrm{HC}=$ healthy control; $\mathrm{PWH}=$ people with HIV; SUVR = standard uptake value ratio. 
A. PET SUVR vs T1 relaxation time in the thalamus
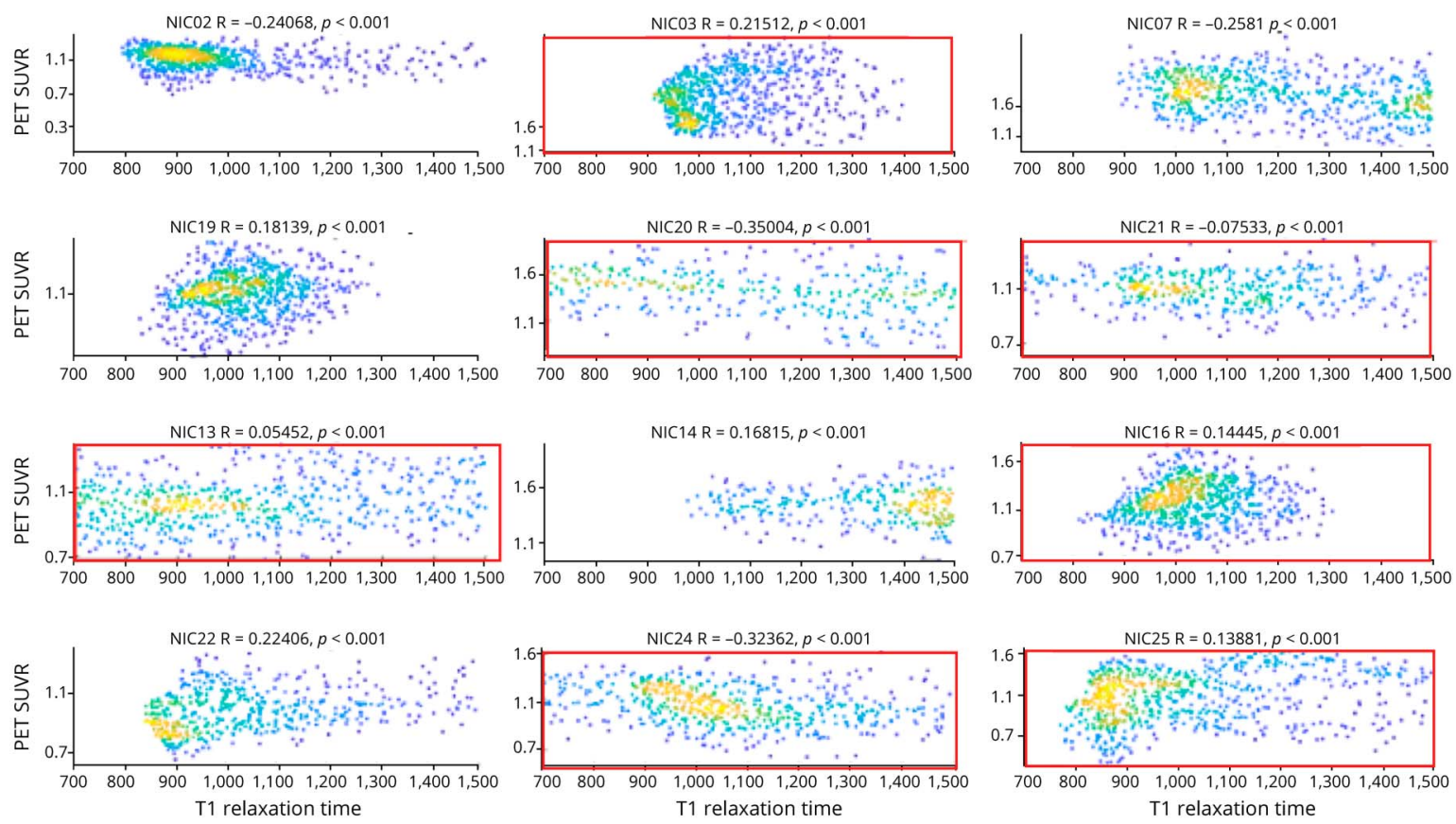

B. PET SUVR vs T2 relaxation time in the thalamus
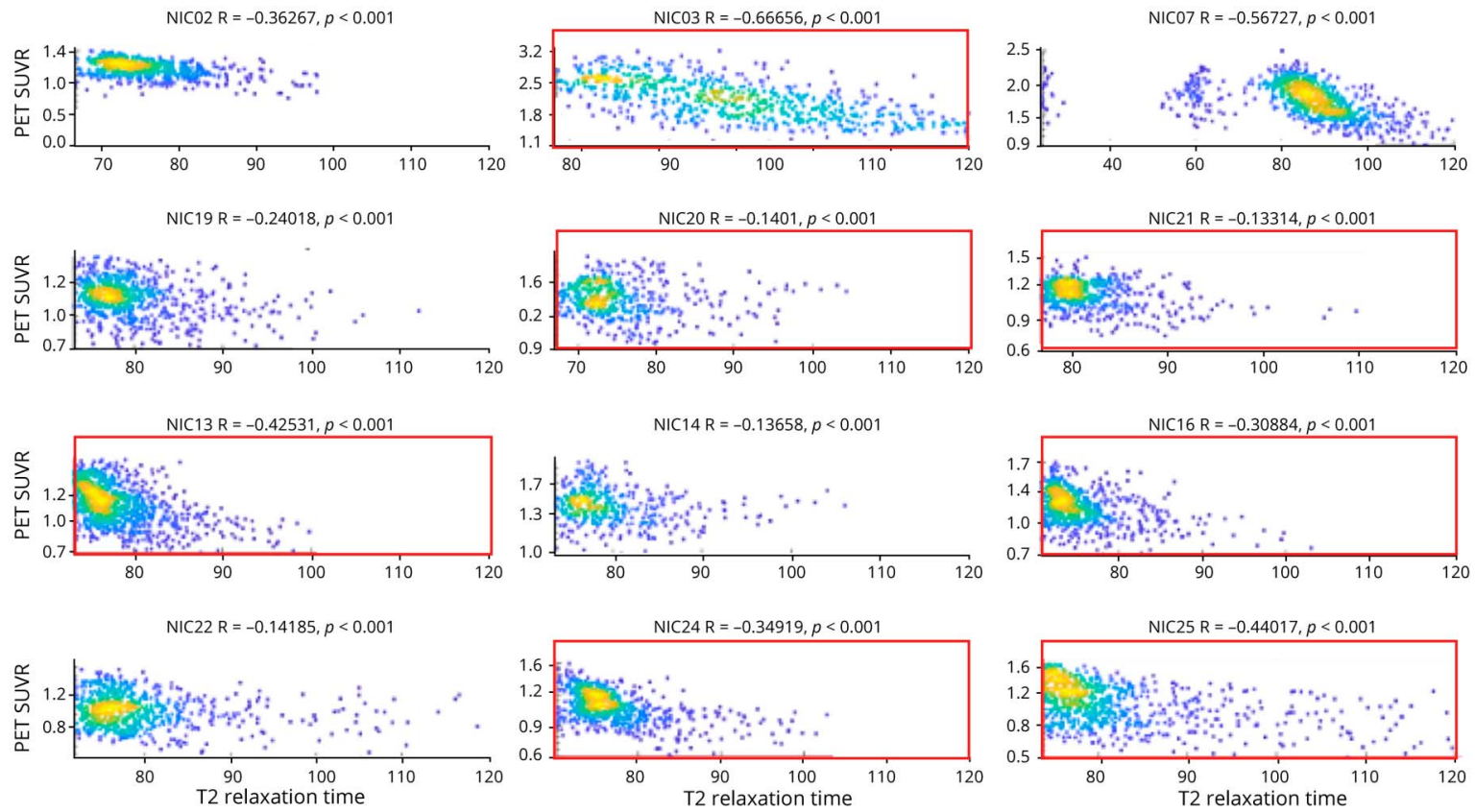

SUVR against T1 relaxation time (A) and T2 relaxation time (B) for each subject's thalamus. The color represents the point density. $R$ is the adjusted $\rho$ value from the Spearman correlation test. Plots in red boxes belong to HABs. HAB = high-affinity binder; SUVR = standard uptake value ratio.

\section{Discussion}

The results of this work demonstrate a significantly greater $\left[{ }^{11} \mathrm{C}\right]$-PBR28 uptake in aviremic PWH on antiretroviral therapy compared with ECs and an overall similar $\left[{ }^{11} \mathrm{C}\right]$ PBR28 SUVR in ECs and HCs, suggesting that ECs spontaneously suppress better neuroinflammation than
PWH on cART. Moreover, our data show that neuroinflammation in PWH is related to tissue changes in qMRI measures that are compatible with loss of tissue integrity and iron accumulation. Finally, our work casts a light into the relationship between PET and qMRI measures of inflammation and cognitive performance in both $\mathrm{PWH}$ and ECs. 
A. PET SUVR vs T1 relaxation time in the white matter
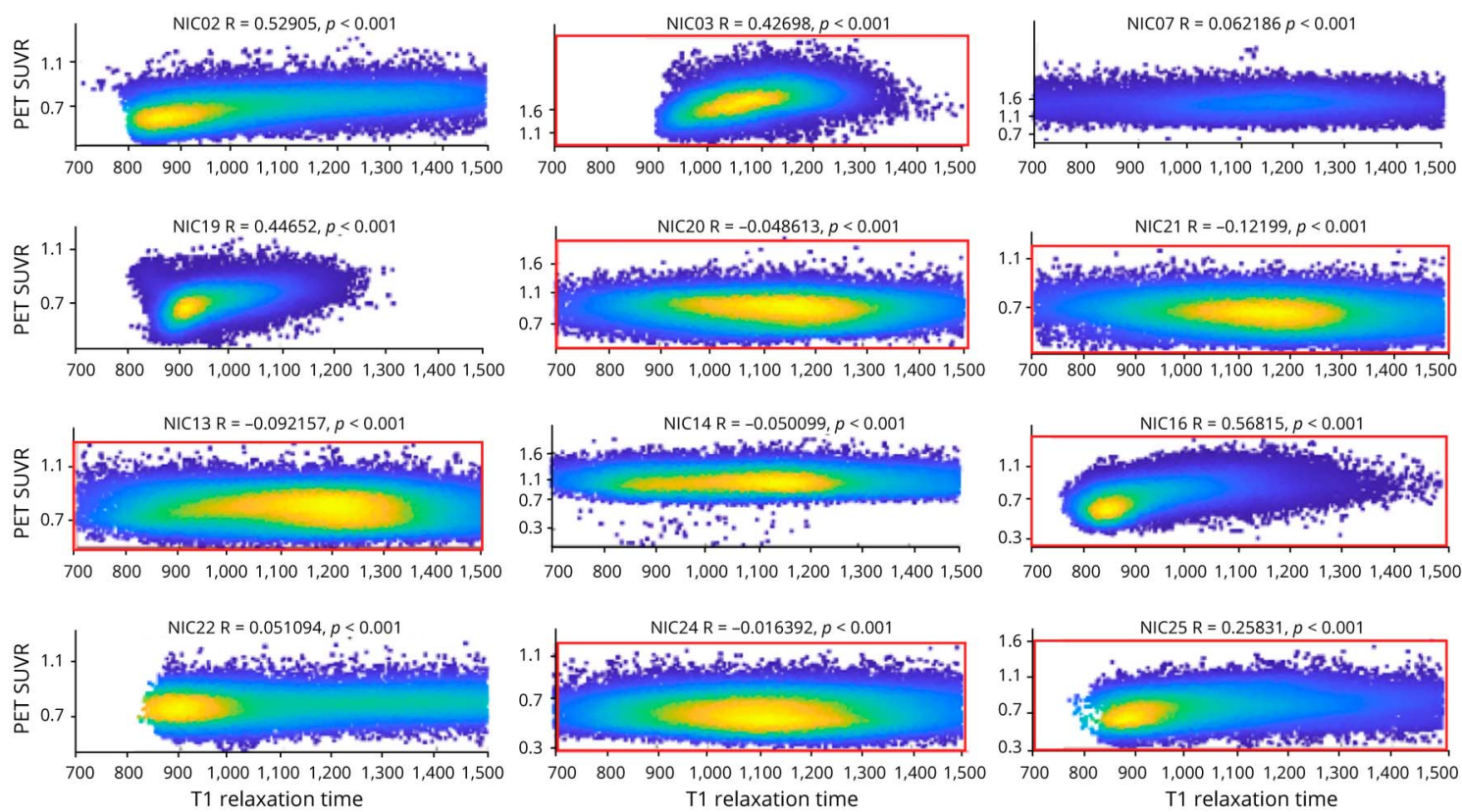

B. PET SUVR vs $T 2$ relaxation time in the white matter
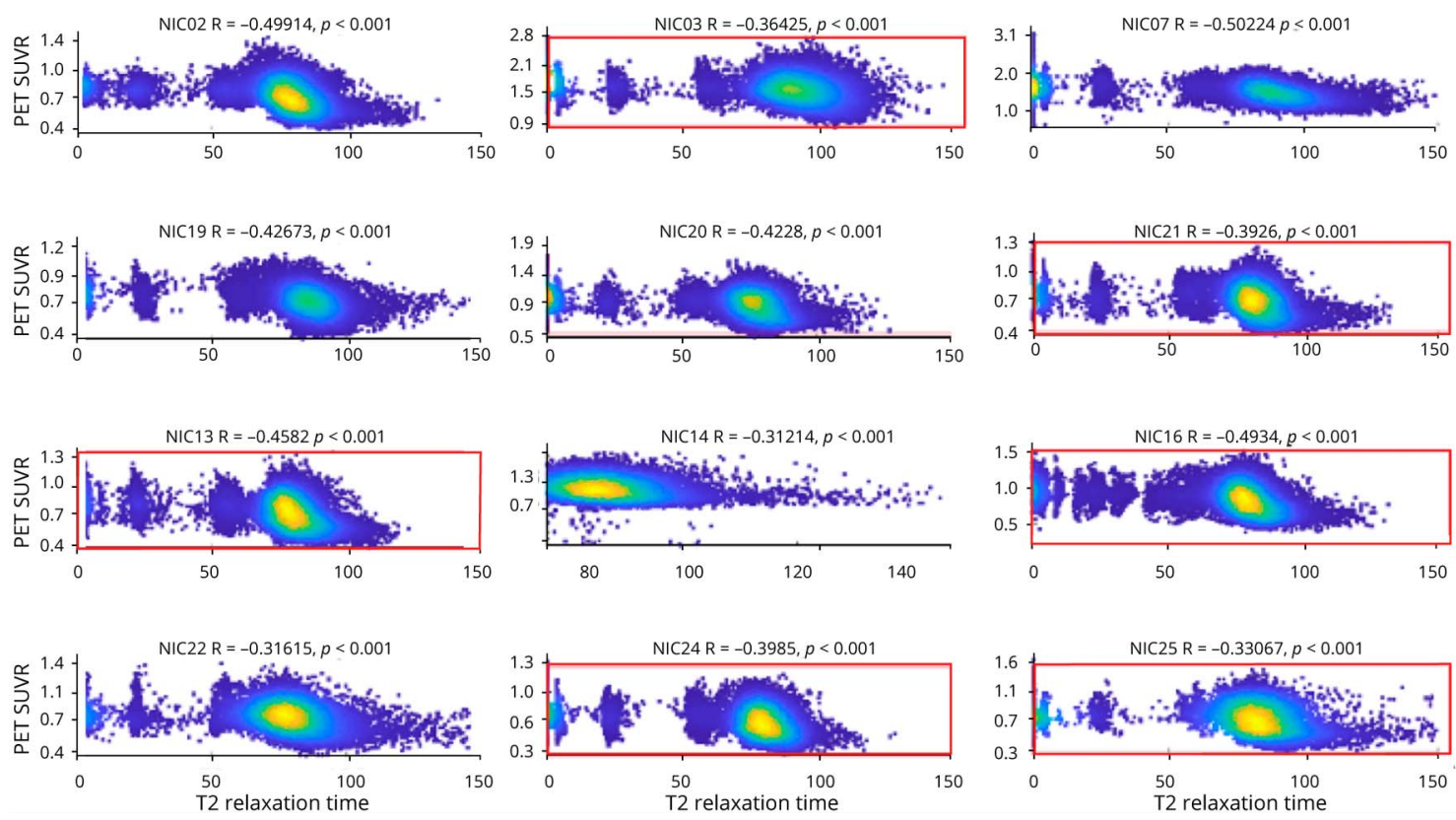

PET SUVR against T1 relaxation time (A) and T2 relaxation time (B) for each subject's white matter. The color represents the points density. $R$ is the adjusted rho value from the Spearman correlation test. Plots in red boxes belong to HABS. HAB = high-affinity binder; SUVR = standard uptake value ratio.

A previous $\left[{ }^{11} \mathrm{C}\right]$-PBR28 $\mathrm{PET}$ study showed that aviremic $\mathrm{PWH}$ on cART exhibit neuroinflammation in different brain areas compared with HIV-negative controls. ${ }^{18}$ In addition, similar results were obtained by using $\left[{ }^{11} \mathrm{C}\right]-\mathrm{DPA}-713 \mathrm{PET}$, which revealed significantly higher glial activation in aviremic $\mathrm{PWH}$ with dementia compared with aviremic PWH without dementia with undetectable viral load. ${ }^{34}$ Our group has also previously shown that optimally treated $\mathrm{PWH}$ with mild neurocognitive impairment show MRI signs of increased brain tissue inflammation and degeneration compared with equally welltreated PWH without HAND and noninfected subjects. ${ }^{35}$

In this work, we extend previous findings ${ }^{18}$ by showing that $\left[{ }^{11} \mathrm{C}\right]$-PBR28 uptake is higher in aviremic PWH on cART than in ECs in numerous brain regions, encompassing subcortical gray matter nuclei (thalamus and putamen), the WM, the hemispheric cortex (precuneus, middle and inferior temporal gyrus, and occipital cortex), and the cerebellum. ECs are a rare group of people 
Table 2 Cognitive Raw Scores and Z-Scores for Individual Tests and Stroop Interference Score for ECs and PWHs

\begin{tabular}{|c|c|c|c|c|c|}
\hline \multirow[b]{2}{*}{ Test name } & \multicolumn{2}{|l|}{$E C(n=5)$} & \multicolumn{2}{|l|}{ PWH (n = 12) } & \multirow{2}{*}{$\frac{p \text { Value }}{\text { Raw score }}$} \\
\hline & Raw score & Z-score & Raw score & Z-score & \\
\hline Trails A & $25.6 \pm 6.9$ & $0.92 \pm 1.15$ & $30.9 \pm 9.2$ & $0.15 \pm 0.86$ & 0.27 \\
\hline Trails B & $80.8 \pm 46.8$ & $-0.03 \pm 2.95$ & $111.4 \pm 55.8$ & $-2.29 \pm 2.99$ & 0.25 \\
\hline Stroop word & $98.0 \pm 17.8$ & $-1.78 \pm 3.13$ & $91.6 \pm 23.9$ & $-0.72 \pm 1.52$ & 0.60 \\
\hline Stroop color & $68.6 \pm 19.6$ & $-1.80 \pm 3.09$ & $64.4 \pm 17.1$ & $-0.90 \pm 1.34$ & 0.66 \\
\hline Stroop color-word & $49.2 \pm 19.1$ & $-0.87 \pm 4.12$ & $36.5 \pm 11.7$ & $-0.15 \pm 1.03$ & 0.11 \\
\hline Stroop interference & $9.2 \pm 12.2$ & $\mathrm{~N} / \mathrm{A}$ & $-0.75 \pm 8.5$ & N/A & 0.07 \\
\hline
\end{tabular}

Abbreviations: $\mathrm{EC}=$ elite controller; N/A = not available; $\mathrm{PWH}=$ people with HIV.

infected with HIV that spontaneously control viral replication in the blood: some of them, like the subjects enrolled in this study, achieve long-standing viral suppression and remain asymptomatic. It was recently shown that EC macaques have SIV harbors in some viral sanctuary sites such as the male reproductive tract, the small bowel, and lymphoid tissue. ${ }^{8}$ To date, however, little is known about the presence of HIV in the brain of ECs.

Results of this study show that there is little evidence of neuroinflammation in the brain of ECs: this may be because HIV is not triggering a chronic low-level inflammatory response as in PWH who require cART to achieve viral suppression. In addition, ECs may be able to prevent the virus to penetrate into the CNS, as suggested by previous studies. ${ }^{36}$ Once HIV penetrates the CNS, it infects glial cells and-in PWH where viral load is controlled by cART - it perpetuates a chronic low-level inflammatory activity. Indeed, neuropathologic, ${ }^{37,38}$ genetic, ${ }^{39}$ and molecular ${ }^{40,41}$ studies in brain specimens and in the CSF showed increased microglia activation, immune responses, and inflammatory biomarkers in PWH with long-term effective therapy. Viral blipping may also occur in virally suppressed PWH on cART, ${ }^{42}$ which may contribute to increased neuroinflammation. Furthermore, cART may not adequately penetrate into the CNS in these $\mathrm{PWH}$ despite peripheral viral suppression ${ }^{43}$ or may be responsible for neurotoxic effects. ${ }^{44}$ Future studies should aim at further investigating the relationship between different cART compounds/viral blipping and neuroinflammation in aviremic PWH on cART.

Our work also provides first evidence that the extent of increase of neuroinflammation, as measured by $\left[{ }^{11} \mathrm{C}\right]-\mathrm{PBR} 28$ uptake, is locally related to a tissue-level increase in $\mathrm{T} 1 \mathrm{rt}$ and decrease in $\mathrm{T} 2$ rt. The T1 and T2 rt depend on water content and its motility, but also on density of micro- and macromolecules in the tissue and on presence of paramagnetic ions, like iron. ${ }^{20}$ The observed increase in $\mathrm{T} 1 \mathrm{rt}$ could be thus explained by loss of tissue microstructure due to HIV infection, directly through the viral infection of glial cells and/or through the immune response to the virus triggering neuroinflammation. Yet, a loss of tissue microstructure is expected to cause an increase in $\mathrm{T} 2 \mathrm{rt}$ : instead, we found a decrease in the mean $\mathrm{T} 2 \mathrm{rt}$ in areas of higher $\left[{ }^{11} \mathrm{C}\right]-\mathrm{PBR} 28$ uptake. This finding may be compatible with an iron accumulation in regions of increased glial metabolism/ $\left[{ }^{11} \mathrm{C}\right]-\mathrm{PBR} 28$ uptake (Figure 6). In fact, previous studies have showed that tissue concentration of non-transferrin-bound iron (NTBI) increases in pathologic conditions associated with neuroinflammation. Iron accumulation is supposed to be associated with changes in the levels of iron transporters due to inflammatory stimuli. ${ }^{45,46}$ Microglia and astrocytes are believed to be primarily responsible for the uptake of NTBI from the extracellular space to prevent extracellular Fenton chemistry, ${ }^{47}$ resulting in colocalization of tissue iron increment and activated glial cells.

Increased iron presence should concomitantly shorten $\mathrm{T} 1$ and $\mathrm{T} 2$ rt. $^{19}$ However, disease-related alterations in iron content might be difficult to be observed by means of $\mathrm{T} 1 \mathrm{rt}$ measurements and might be overshadowed by any changes in water content or loss of micro- and macromolecules, which affect $\mathrm{T} 2 \mathrm{rt}$ in a lesser extent. ${ }^{20}$ Altogether, an increased tissue iron content coupled with moderate loss of tissue microstructure represents a plausible explanation for the obtained qMRI results (Figure 6).

Of interest, $\mathrm{PWH}$ and ECs showed mild deficits in executive functioning skills, including visuomotor speed, cognitive set shifting, and response inhibition. Nevertheless, the processing speed and selective attention of these subjects were positively related to the uptake of $\left[{ }^{11} \mathrm{C}\right]-\mathrm{PBR} 28$ in WM and to its integrity measured with $\mathrm{T} 1$ relaxometry. This suggests that the presence of low-grade chronic inflammatory activity in aviremic PWH and ECs does not directly affect cognition but rather stimulate the parallel development of compensatory mechanisms leading to normal executive functioning.

Our study has some limitations related to the small sample size and to the absence of a true reference region for our $\left[{ }^{11} \mathrm{C}\right]$ PBR28 analyses due to rarity of ECs and to the absence of a region devoid of TSPO, respectively. Furthermore, because of the invasiveness of radiometabolite-corrected arterial input function measurement techniques and other practical limitations, no dynamic PET data were available for fully quantitative PET measurements (i.e., binding potential and distribution volume ratio). These results would need to be replicated with fully quantitative PET imaging. In this work, we studied the 

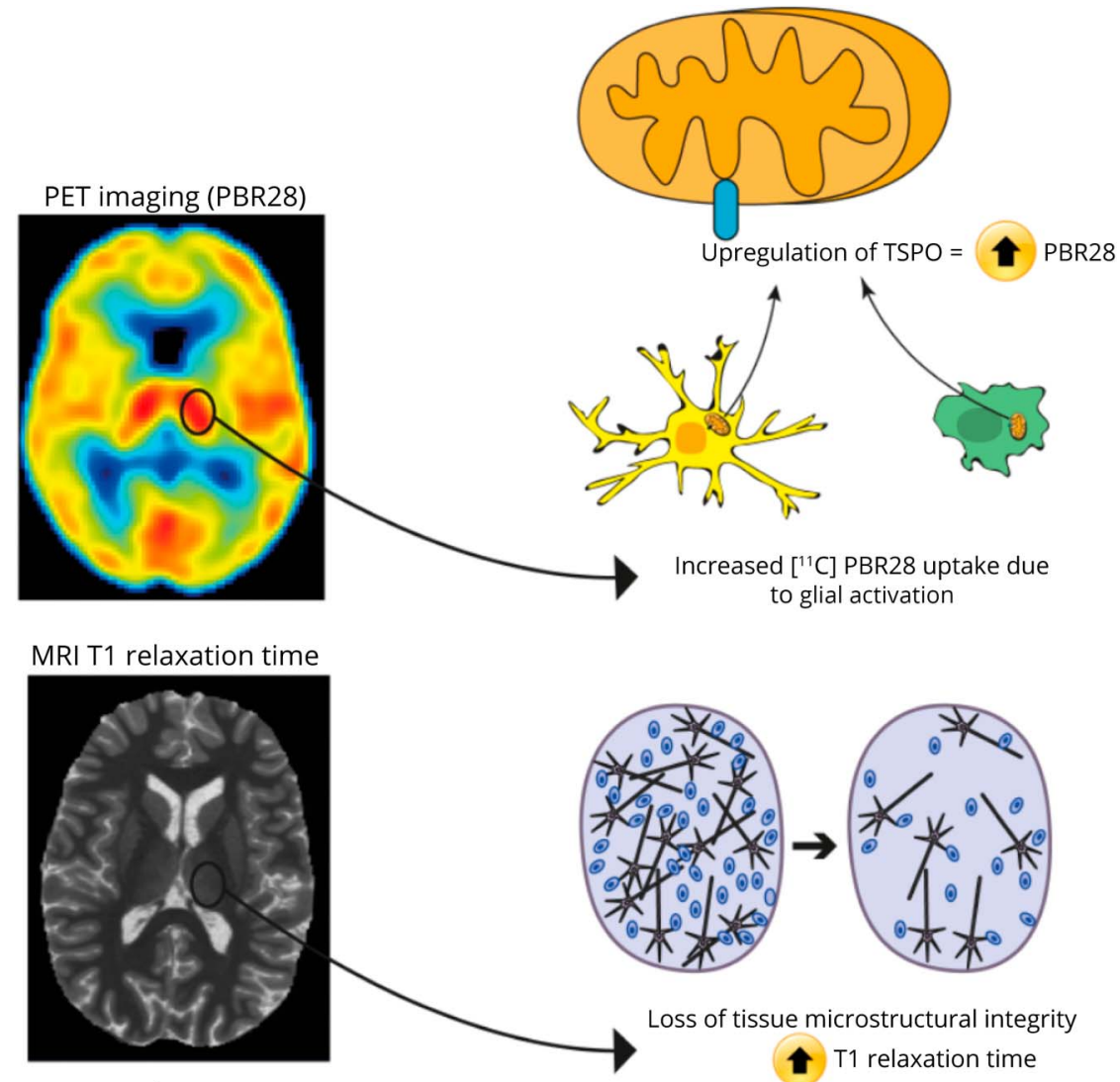

MRI T2 relaxation time
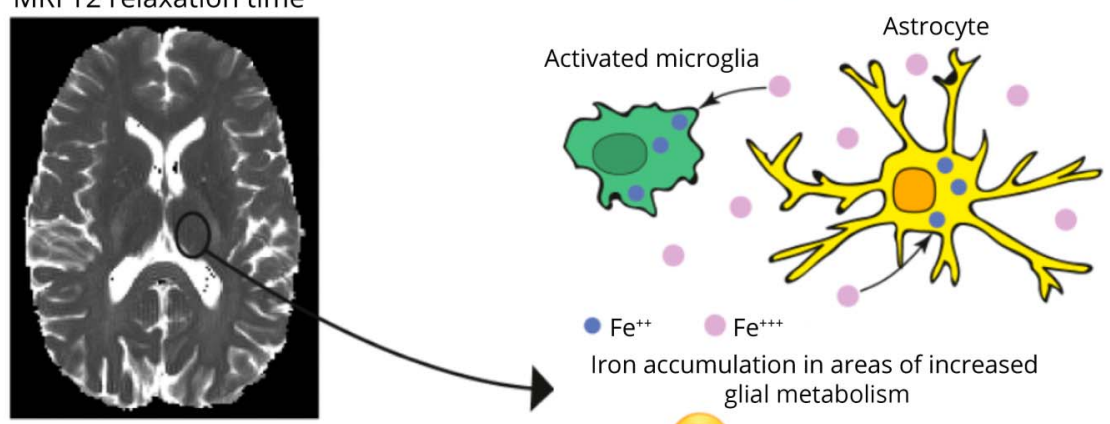

Iron accumulation in areas of increased glial metabolism

$\mathrm{T} 2$ relaxation time

TSPO = translocator protein $18 \mathrm{kDa}$.

relationship between PET and quantitative T1 and T2 relaxometry measurements in the thalamus and WM. The choice of these structures was motivated by the association between WM/ thalamus abnormalities and cognitive impairment in $\mathrm{PWH}$ in previous studies ${ }^{48,49}$ and by their involvement in neuroinflammation in other brain disorders. ${ }^{27,50}$ Future works should extend our observations to other brain regions where other studies have demonstrated pathophysiologic changes linked to neuropsychological alterations in this patient population, such as frontal and parietal cortical areas, cingulate cortex, and basal ganglia. ${ }^{51}$ We also lack $\mathrm{T} 1$ and $\mathrm{T} 2$ relaxometry acquisitions in HCs because those sequences were not available at the time when PET/MRI was performed in these subjects. Future studies should hence confirm the observed relationship between molecular and tissular markers of neuroinflammation in a larger group of brain regions in other patients populations and healthy subjects. Our study also included only 3 tests to assess the cognitive function. A more comprehensive neuropsychological assessment will be needed to further study the links between neuroinflammation and cognitive function in PWH and ECs.

In conclusion, the results of this work demonstrate significantly lower $\left[{ }^{11} \mathrm{C}\right]-\mathrm{PBR} 28$ signal in ECs compared with PWH patients on therapy, suggesting that the former might be able to better control neuroinflammation. This work also shows the complementarity of PET-related metabolic information with microstructural knowledge derived from quantitative MRI in the study of neuroinflammation. 


\section{Acknowledgment}

The authors thank Grae Arabasz, Regan Butterfield, Shirley $\mathrm{Hsu}$, and Atreyi Saha for helping with data acquisition.

\section{Study Funding}

This work has been supported by the Milton Fund of Harvard University, the Campbell Foundation, and 1R01DA04708801 (M.L.L. and E.R.). S.S. Mukerji was supported by the Harvard University Center for AIDS Research and K23MH115812 (S.S.M.). R.T. Gandhi receives grant funding from the Harvard University Center for AIDS Research (NIH P30 AI060354) and the AIDS Clinical Trials Group (NIH/ NIAID 2 UMAI069412-09). C. Granziera is supported by the Swiss National Science Foundation (SNSF) grant PP00P3 176984, the Stiftung zur Förderung der gastroenterologischen und allgemeinen klinischen Forschung and the EUROSTAR E!113682 HORIZON2020.

\section{Disclosure}

The authors report no disclosures. Go to Neurology.org/NN for full disclosures.

\section{Publication History}

Received by Neurology: Neuroimmunology \& Neuroinflammation August 1, 2021. Accepted in final form December 15, 2021. Submitted and externally peer reviewed. The handling editor was Dennis L. Kolson, MD, PhD.

\begin{tabular}{|c|c|c|}
\hline Name & Location & Contribution \\
\hline $\begin{array}{l}\text { Hasan Sari, } \\
\text { PhD }\end{array}$ & $\begin{array}{l}\text { MGH/MIT/HMS Athinoula A. } \\
\text { Martinos Center for } \\
\text { Biomedical Imaging, } \\
\text { Massachusetts General } \\
\text { Hospital, Harvard Medical } \\
\text { School, Charlestown }\end{array}$ & $\begin{array}{l}\text { Drafting/revision of the } \\
\text { manuscript for content, } \\
\text { including medical writing for } \\
\text { content, and analysis or } \\
\text { interpretation of data }\end{array}$ \\
\hline $\begin{array}{l}\text { Riccardo } \\
\text { Galbusera, } \\
\text { PhD }\end{array}$ & $\begin{array}{l}\text { Neurologic Clinic and } \\
\text { Policlinic, Departments of } \\
\text { Medicine, Clinical Research } \\
\text { and Biomedical Engineering, } \\
\text { University Hospital Basel and } \\
\text { University of Basel; } \\
\text { Translational Imaging in } \\
\text { Neurology (ThINk) Basel, } \\
\text { Department of Biomedical } \\
\text { Engineering, University } \\
\text { Hospital Basel and University } \\
\text { of Basel, Switzerland }\end{array}$ & $\begin{array}{l}\text { Drafting/revision of the } \\
\text { manuscript for content, } \\
\text { including medical writing for } \\
\text { content, and analysis or } \\
\text { interpretation of data }\end{array}$ \\
\hline $\begin{array}{l}\text { Guillaume } \\
\text { Bonnier, } \\
\text { PhD }\end{array}$ & $\begin{array}{l}\text { Neurologic Clinic and } \\
\text { Policlinic, Departments of } \\
\text { Medicine, Clinical Research } \\
\text { and Biomedical Engineering, } \\
\text { University Hospital Basel and } \\
\text { University of Basel; } \\
\text { Translational Imaging in } \\
\text { Neurology (ThINk) Basel, } \\
\text { Department of Biomedical } \\
\text { Engineering, University } \\
\text { Hospital Basel and University } \\
\text { of Basel, Switzerland }\end{array}$ & $\begin{array}{l}\text { Drafting/revision of the } \\
\text { manuscript for content, } \\
\text { including medical writing for } \\
\text { content, and analysis or } \\
\text { interpretation of data }\end{array}$ \\
\hline
\end{tabular}

Appendix (continued)

\begin{tabular}{lll}
\hline Name & Location & Contribution \\
\hline Yang Lin, & MGH/MIT/HMS Athinoula A. & $\begin{array}{l}\text { Drafting/revision of the } \\
\text { manuscript for content, } \\
\text { MS }\end{array}$ \\
$\begin{array}{ll}\text { Martinos Center for } \\
\text { Biomedical Imaging, } \\
\text { Massachusetts General } \\
\text { Hospital, Harvard Medical } \\
\text { School, Charlestown }\end{array}$ & $\begin{array}{l}\text { content, and analysis or } \\
\text { interpretation of data }\end{array}$ \\
& \\
\hline
\end{tabular}

\begin{tabular}{lll}
\hline $\begin{array}{l}\text { Zeynab } \\
\text { Alshelh, } \\
\text { PhD }\end{array}$ & $\begin{array}{l}\text { MGH/MIT/HMS Athinoula A. } \\
\text { Martinos Center for } \\
\text { Biomedical Imaging, } \\
\text { Massachusetts General } \\
\text { Hospital, Harvard Medical } \\
\text { School, Charlestown }\end{array}$ & $\begin{array}{l}\text { Drafting/revision of the } \\
\text { manuscript for content, } \\
\text { including medical writing for } \\
\text { content, and major role in the } \\
\text { acquisition of data }\end{array}$ \\
\hline $\begin{array}{l}\text { Angel } \\
\text { Torrado- } \\
\text { Carvajal, } \\
\text { PhD }\end{array}$ & $\begin{array}{l}\text { MGH/MIT/HMS Athinoula A. } \\
\text { Biomedical Imaging, }\end{array}$ & $\begin{array}{l}\text { Drafting/revision of the } \\
\text { manuscript for content, } \\
\text { including medical writing for } \\
\text { content, and major role in the } \\
\text { acquisition of data }\end{array}$ \\
& $\begin{array}{l}\text { Hospital, Harvard Medical } \\
\text { School, Charlestown; Medical } \\
\text { Image Analysis and Biometry } \\
\text { Lab, Universidad Rey Juan }\end{array}$ & \\
& Carlos, Madrid, Spain & \\
&
\end{tabular}

Shibani S. Department of Neurology, Drafting/revision of the

Mukerji, Massachusetts General manuscript for content,

MD, PhD Hospital, Boston including medical writing for content; major role in the acquisition of data; and study concept or design

\begin{tabular}{lll}
\hline Eva M. & MGH/MIT/HMS Athinoula A. & $\begin{array}{l}\text { Drafting/revision of the } \\
\text { Ratai, PhD }\end{array}$ \\
$\begin{array}{ll}\text { Martinos Center for } \\
\text { Biomedical Imaging, } \\
\text { Massachusetts General }\end{array}$ & $\begin{array}{l}\text { including medical writing for } \\
\text { content, and study concept } \\
\text { Hospital, Harvard Medical } \\
\text { School, Charlestown }\end{array}$ & $\begin{array}{l}\text { or design } \\
\end{array}$
\end{tabular}

Rajesh T. Department of Neurology, Drafting/revision of the

Gandhi, MD Massachusetts General manuscript for content, Hospital, Boston including medical writing for content, and major role in the acquisition of data

\begin{tabular}{ll}
\hline Jacqueline & Infectious Diseases, \\
T. Chu, PhD & Massachusetts General \\
& Hospital, Boston
\end{tabular}

Drafting/revision of the manuscript for content, including medical writing for content; major role in the acquisition of data; and analysis or interpretation of data

\begin{tabular}{lll}
\hline $\begin{array}{l}\text { Oluwaseun } \\
\text { Akeju, MD }\end{array}$ & $\begin{array}{l}\text { Department of Anesthesia, } \\
\text { Massachusetts General } \\
\text { Hospital, Boston }\end{array}$ & $\begin{array}{l}\text { Drafting/revision of the } \\
\text { manuscript for content, } \\
\text { including medical writing for } \\
\text { content, and major role in the } \\
\text { acquisition of data }\end{array}$ \\
$\begin{array}{l}\text { Vwaire } \\
\text { Orhurhu, } \\
\text { PhD }\end{array}$ & $\begin{array}{l}\text { Department of Anesthesia, } \\
\text { Massachusetts General }\end{array}$ & $\begin{array}{l}\text { Drafting/revision of the } \\
\text { manuscript for content, } \\
\text { including medical writing for } \\
\text { content, and major role in the } \\
\text { acquisition of data }\end{array}$
\end{tabular}

\section{Andrew N. MGH/MIT/HMS Athinoula A. Drafting/revision of the} Salvatore, Martinos Center for Biomedical manuscript for content, MS Imaging, Massachusetts including medical writing for General Hospital, Harvard content, and analysis or Medical School, Charlestown interpretation of data

\begin{tabular}{lll}
\hline Janet & Department of Psychiatry, & Drafting/revision of the \\
Sherman, & Massachusetts General & manuscript for content, \\
PhD & Hospital, Boston & $\begin{array}{l}\text { including medical writing for } \\
\text { content, and major role in the } \\
\end{array}$ \\
& acquisition of data
\end{tabular}


Appendix (continued)

\begin{tabular}{lll}
\hline Name & Location & Contribution \\
\hline $\begin{array}{l}\text { Douglas S. } \\
\text { Kwon, MD, }\end{array}$ & Ragon Institute of MGH, MIT & and Harvard, Cambridge \\
PhD & & $\begin{array}{l}\text { Drafting/revision of the } \\
\text { manuscript for content, } \\
\text { including medical writing for } \\
\text { content, and major role in th } \\
\text { acquisition of data }\end{array}$
\end{tabular}

Bruce Ragon Institute of MGH, MIT Major role in the acquisition Walker, MD and Harvard, Cambridge of data

\begin{tabular}{lll}
\hline Bruce & MGH/MIT/HMS Athinoula A. & Drafting/revision of the \\
Rosen, MD, & Martinos Center for & manuscript for content, \\
PhD & Biomedical Imaging, & including medical writing for \\
& Massachusetts General & content \\
& Hospital, Harvard Medical &
\end{tabular}
School, Charlestown

\begin{tabular}{lll}
\hline $\begin{array}{l}\text { Julie C. } \\
\text { Price, PhD }\end{array}$ & $\begin{array}{l}\text { MGH/MIT/HMS Athinoula A. } \\
\text { Martinos Center for } \\
\text { Biomedical Imaging, } \\
\text { Massachusetts General } \\
\text { Hospital, Harvard Medical } \\
\text { School, Charlestown }\end{array}$ & $\begin{array}{l}\text { Drafting/revision of the } \\
\text { manuscript for content, } \\
\text { including medical writing for } \\
\text { content, and analysis or } \\
\text { interpretation of data }\end{array}$ \\
\hline Lauren E. & $\begin{array}{l}\text { Department of Psychiatry, } \\
\text { Pollak, PhD } \\
\text { Massachusetts General } \\
\text { Hospital, Boston }\end{array}$ & $\begin{array}{l}\text { Drafting/revision of the } \\
\text { manuscript for content, } \\
\text { including medical writing for } \\
\text { content; major role in the } \\
\text { acquisition of data; and } \\
\text { analysis or interpretation of } \\
\text { data }\end{array}$ \\
\hline
\end{tabular}

Marco L. MGH/MIT/HMS Athinoula A.

Loggia, PhD Martinos Center for Biomedical Imaging, Massachusetts General Hospital, Harvard Medical School, Charlestown

\section{Drafting/revision of the} manuscript for content, including medical writing for content; major role in the acquisition of data; study concept or design; and analysis or interpretation of data

\begin{tabular}{|c|c|c|}
\hline $\begin{array}{l}\text { Cristina } \\
\text { Granziera, } \\
\text { MD, PhD }\end{array}$ & $\begin{array}{l}\text { Neurologic Clinic and } \\
\text { Policlinic, Departments of } \\
\text { Medicine, Clinical Research } \\
\text { and Biomedical Engineering, } \\
\text { University Hospital Basel and } \\
\text { University of Basel; } \\
\text { Translational Imaging in } \\
\text { Neurology (ThINk) Basel, } \\
\text { Department of Biomedical } \\
\text { Engineering, University } \\
\text { Hospital Basel and University } \\
\text { of Basel, Switzerland }\end{array}$ & $\begin{array}{l}\text { Drafting/revision of the } \\
\text { manuscript for content, } \\
\text { including medical writing for } \\
\text { content; major role in the } \\
\text { acquisition of data; study } \\
\text { concept or design; and } \\
\text { analysis or interpretation of } \\
\text { data }\end{array}$ \\
\hline
\end{tabular}

\section{References}

1. Ellis RJ, Calero P, Stockin MD. HIV infection and the central nervous system: a primer. Neuropsychol Rev. 2009;19(2):144-151.

2. Denton PW, Søgaard OS, Tolstrup M. Impacts of HIV cure interventions on viral reservoirs in tissues. Front Microbiol. 2019;10:1956. doi: 10.3389/fmicb.2019.01956.

3. Rojas-Celis V, Valiente-Echeverría F, Soto-Rifo R, et al. New challenges of HIV-1 infection: how HIV-1 attacks and resides in the central nervous system. Cells. 2019; 8(10): 1245. doi: $10.3390 /$ cells8101245.

4. Wallet C, de Rovere M, van Assche J, et al. Microglial cells: the main HIV-1 reservoir in the brain. Front Cell Infect Microbiol. 2019;9:362. doi: 10.3389/fcimb.2019.00362.

5. Clifford DB, Ances BM. HIV-associated neurocognitive disorder. Lancet Infect Dis. 2013;13(11):976-986.

6. Deeks SG, Walker BD. Human immunodeficiency virus controllers: mechanisms of durable virus control in the absence of antiretroviral therapy. Immunity. 2007;27(3): 406-416.

7. Casado C, Galvez C, Pernas M, et al. Permanent control of HIV-1 pathogenesis in exceptional elite controllers: a model of spontaneous cure. Sci Rep. 2020;10(1):1902. doi: 10.1038/s41598-020-58696-y.

8. Santangelo PJ, Rogers KA, Zurla C, et al. Whole-body immunoPET reveals active SIV dynamics in viremic and antiretroviral therapy-treated macaques. Nat Methods. 2015; 12(5):427-432

9. Chen MK, Guilarte TR. Translocator protein $18 \mathrm{kDa}$ (TSPO): molecular sensor of brain injury and repair. Pharmacol Ther. 2008;118(1):1-17.
10. Rupprecht R, Papadopoulos V, Rammes G, et al. Translocator protein (18 kDa) (TSPO) as a therapeutic target for neurological and psychiatric disorders. Nat Rev Drug Discov. 2010;9(12):971-988.

11. Venneti S, Lopresti BJ, Wiley CA. The peripheral benzodiazepine receptor (translocator protein $18 \mathrm{kDa}$ ) in microglia: from pathology to imaging. Prog Neurobiol. 2006;80(6):308-322.

12. Liu GJ, Middleton RJ, Hatty CR, et al. The $18 \mathrm{kDa}$ translocator protein, microglia and neuroinflammation. Brain Pathol. 2014;24(6):631-653.

13. Shen Z, Bao X, Wang R. Clinical PET imaging of microglial activation: implications for microglial therapeutics in Alzheimer's disease. Front Aging Neurosci. 2018;10:314. doi: 10.3389 /fnagi.2018.00314.

14. Owen DR, Howell OW, Tang SP, et al. Two binding sites for 3 HPBR28 in human brain: implications for TSPO PET imaging of neuroinflammation.J Cereb Blood Flow Metab. 2010;30(9):1608-1618.

15. Loggia ML, Chonde DB, Akeju O, et al. Evidence for brain glial activation in chronic pain patients. Brain. 2015;138(pt 3):604-615.

16. Banati RB, Newcombe J, Gunn RN, et al. The peripheral benzodiazepine binding site in the brain in multiple sclerosis. Quantitative in vivo imaging of microglia as a measure of disease activity. Brain. 2000;123(pt 11):2321-2337.

17. Zürcher NR, Loggia ML, Lawson R, et al. Increased in vivo glial activation in patients with amyotrophic lateral sclerosis: assessed with [11C]-PBR28. Neuroimage Clin. 2015;7:409-414

18. Vera JH, Guo Q, Cole JH, et al. Neuroinflammation in treated HIV-positive individuals: a TSPO PET study. Neurology. 2016;86(15):1425-1432.

19. Deoni SCL. Quantitative relaxometry of the brain. Top Magn Reson Imaging. 2010; 21(2):101-113.

20. Gelman N, Ewing JR, Gorell JM, et al. Interregional variation of longitudinal relaxation rates in human brain at 3.0 T: relation to estimated iron and water contents. Magn Reson Med. 2001;45(1):71-79.

21. Izquierdo-Garcia D, Hansen AE, Förster S, et al. An SPM8-based approach for attenuation correction combining segmentation and nonrigid template formation: application to simultaneous PET/MR Brain Imaging. J Nucl Med. 2014;55(11): $1825-1830$

22. Catana C, Chonde DB, Chen KT, et al. Combined MR-assisted motion and partial volume effects corrections - impact on PET data quantification. EJNMMI Phys. 2014 1(suppl 1):A38. doi: 10.1186/2197-7364-1-s1-a38.

23. Sumpf TJ, Uecker M, Boretius S, et al. Model-based nonlinear inverse reconstruction for T2 mapping using highly undersampled spin-echo MRI. J Magn Reson Imaging. 2011;34(2):420-428.

24. Jenkinson M, Beckmann CF, Behrens TEJ, et al. Review FSL. Neuroimage. 2012; 62(2):782-790.

25. Desikan RS, Ségonne F, Fischl B, et al. An automated labeling system for subdividing the human cerebral cortex on MRI scans into gyral based regions of interest. Neuroimage. 2006;31(3):968-980.

26. Lois C, González I, Izquierdo-García D, et al. Neuroinflammation in Huntington's disease: new insights with 11C-PBR28 PET/MRI. ACS Chem Neurosci. 2018;9(11) 2563-2571. doi: 10.1021/acschemneuro.8b00072.

27. Albrecht DS, Kim M, Akeju O, et al. The neuroinflammatory component of negative affect in patients with chronic pain. Mol Psychiatry. 2021;26(3):864-874. doi 10.1038/s41380-019-0433-1.

28. Albrecht DS, Normandin MD, Shcherbinin S, et al. Pseudoreference regions for glial imaging with 11 C-PBR28: investigation in 2 clinical cohorts. J Nucl Med. 2018;59(1): 107-114

29. Albrecht DS, Mainero C, Ichijo E, et al. Imaging of neuroinflammation in migraine with aura: a [11C]PBR28 PET/MRI study. Neurology. 2019;92(17):E2038-E2050.

30. Roche A, Forbes F. Partial volume estimation in brain MRI revisited. In: Lecture Notes in Computer Science (Including Subseries Lecture Notes in Artificial Intelligence and Lecture Notes in Bioinformatics). Springer; 2014:771-778.

31. Reitan RM. Validity of the trail making test as an indicator of organic brain damage. Perceptual Mot Skills. 1958;8(3):271-276. doi: 10.2466/pms.1958.8.3.271.

32. Golden CJ. Stroop Color and Word Test: A Manual for Clinical and Experimental Uses. Stoelting; 2017.

33. Tombaugh TN. Trail making test A and B: normative data stratified by age and education Arch Clin Neuropsychol. 2004;19(2):203-214. doi: 10.1016/S0887-6177(03)00039-8.

34. Coughlin JM, Wang Y, Ma S, et al. Regional brain distribution of translocator protein using [11C]DPA-713 PET in individuals infected with HIV. J Neurovirol. 2014;20(3):219-232.

35. Granziera C, Daducci A, Simioni S, et al. Micro-structural brain alterations in aviremic HIV+ patients with minor neurocognitive disorders: a multi-contrast study at high field. PLoS One. 2013;8(9):e72547. doi: 10.1371/journal.pone.0072547.

36. Dahl V, Peterson J, Spudich S, et al. Single-copy assay quantification of HIV-1 RNA in paired cerebrospinal fluid and plasma samples from elite controllers. AIDS. 2013; 27(7):1145-1149.

37. Tavazzi E, Morrison D, Sullivan P, et al. Brain inflammation is a common feature of HIV-infected patients without HIV encephalitis or productive brain infection. Cur HIV Res. 2014;12(2):97-110.

38. Anthony IC, Ramage SN, Carnie FW, et al. Influence of HAART on HIV-related CNS disease and neuroinflammation. J Neuropathol Exp Neurol. 2005;64(6):529-536.

39. Borjabad A, Morgello S, Chao W, et al. Significant effects of antiretroviral therapy on globa gene expression in brain tissues of patients with HIV-1-associated neurocognitive disorders. PLoS Pathog. 2011;7(9):e1002213. doi: 10.1371/journal.ppat.1002213.

40. Edén A, Price RW, Spudich S, et al. Immune activation of the central nervous system is still present after $>4$ years of effective highly active antiretroviral therapy. $J$ Infect Dis. 2007;196(12):1779-1783. 
41. Yilmaz A, Price RW, Spudich S, et al. Persistent intrathecal immune activation in HIV1-infected individuals on antiretroviral therapy. J Acquir Immune Defic Syndrome. 2008; 47(2):168-173

42. Young J, Rickenbach M, Calmy A, et al. Transient detectable viremia and the risk of viral rebound in patients from the Swiss HIV Cohort Study. BMC Infect Dis. 2015;15:382.

43. Carvalhal A, Gill MJ, Letendre SL, et al. Central nervous system penetration effectiveness of antiretroviral drugs and neuropsychological impairment in the Ontario HIV Treatment Network Cohort Study. J Neurovirol. 2016;22(3):349-357.

44. Yuan NY, Kaul M. Beneficial and adverse effects of cART affect neurocognitive function in HIV-1 infection: balancing viral suppression against neuronal stress and injury. J Neuroimmune Pharmacol. 2021;16(1):90-112.

45. Urrutia P, Aguirre P, Esparza A, et al. Inflammation alters the expression of DMT1, FPN1 and hepcidin, and it causes iron accumulation in central nervous system cells. J Neurochem. 2013;126(4):541-549.
46. Pelizzoni I, Zacchetti D, Campanella A, et al. Iron uptake in quiescent and inflammation-activated astrocytes: a potentially neuroprotective control of iron burden. Biochim Biophys Acta. 2013;1832(8):1326-1333.

47. Dringen R, Bishop GM, Koeppe $M$, et al. The pivotal role of astrocytes in the metabolism of iron in the brain. Neurochem Res. 2007;32(11):1884-1890.

48. Alakkas A, Ellis RJ, Watson CWM, et al. White matter damage, neuroinflammation, and neuronal integrity in HAND. J Neurovirol. 2019;25(1):32-41.

49. Sanford R, Fellows LK, Ances BM, et al. Association of brain structure changes and cognitive function with combination antiretroviral therapy in HIV-positive individuals. JAMA Neurol. 2018;75(1):72-79.

50. Torrado-Carvajal A, Toschi N, Albrecht DS, et al. Thalamic neuroinflammation as a reproducible and discriminating signature for chronic low back pain. Pain. 2021; 162(4):1241-1249.

51. Ances BM, Hammoud DA. Neuroimaging of HIV-associated neurocognitive disorders (HAND). Curr Opin HIV AIDS. 2014;9(6):545-551. 


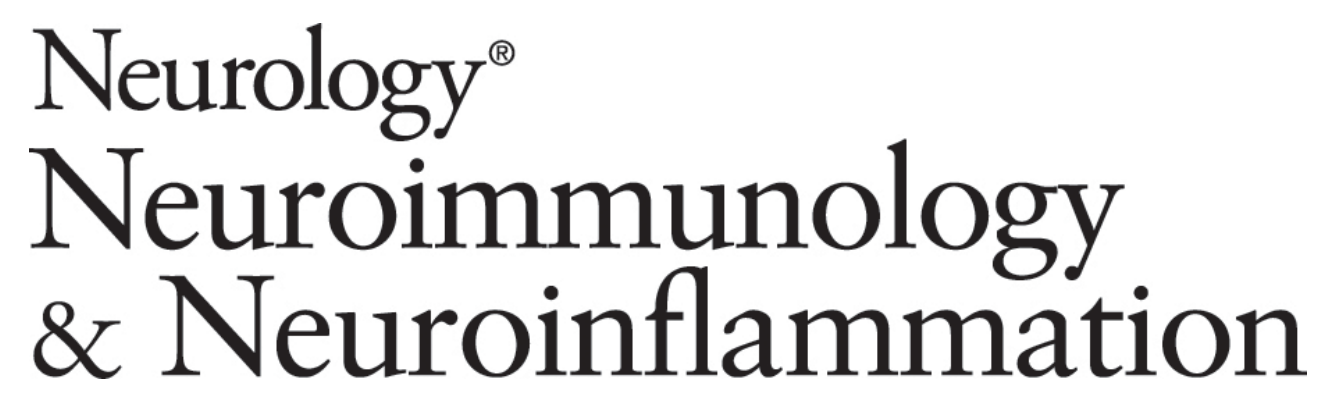
Multimodal Investigation of Neuroinflammation in Aviremic Patients With HIV on Antiretroviral Therapy and HIV Elite Controllers
Hasan Sari, Riccardo Galbusera, Guillaume Bonnier, et al.
Neurol Neuroimmunol Neuroinflamm 2022;9;
DOI 10.1212/NXI.0000000000001144

This information is current as of February 9, 2022

Neurol Neuroimmunol Neuroinflamm is an official journal of the American Academy of Neurology.

Published since April 2014, it is an open-access, online-only, continuous publication journal. Copyright

Copyright $\odot 2022$ The Author(s). Published by Wolters Kluwer Health, Inc. on behalf of the American

Academy of Neurology.. All rights reserved. Online ISSN: 2332-7812.

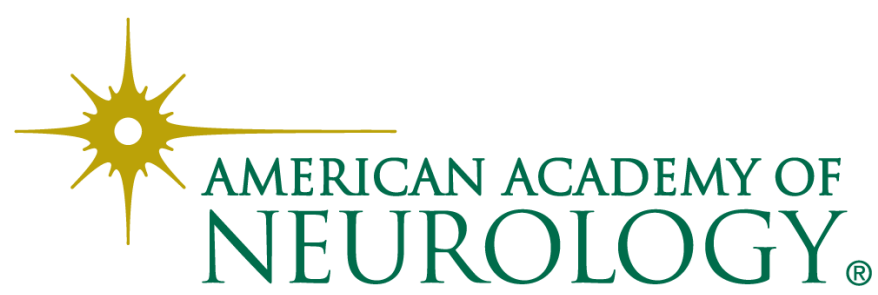




\section{Updated Information \& Services}

References

Citations

Subspecialty Collections

Errata

Permissions \& Licensing

\section{Reprints}

including high resolution figures, can be found at: http://nn.neurology.org/content/9/2/e1144.full.html

This article cites 49 articles, 2 of which you can access for free at: http://nn.neurology.org/content/9/2/e1144.full.html\#\#ref-list-1

This article has been cited by 2 HighWire-hosted articles: http://nn.neurology.org/content/9/2/e1144.full.html\#\#otherarticles

This article, along with others on similar topics, appears in the following collection(s):

\section{HIV}

http://nn.neurology.org//cgi/collection/hiv

\section{MRI}

http://nn.neurology.org//cgi/collection/mri

\section{PET}

http://nn.neurology.org//cgi/collection/pet

An erratum has been published regarding this article. Please see next page or:

/content/9/4/e1175.full.pdf

Information about reproducing this article in parts (figures,tables) or in its entirety can be found online at:

http://nn.neurology.org/misc/about.xhtml\#permissions

Information about ordering reprints can be found online:

http://nn.neurology.org/misc/addir.xhtml\#reprintsus

Neurol Neuroimmunol Neuroinflamm is an official journal of the American Academy of Neurology.

Published since April 2014, it is an open-access, online-only, continuous publication journal. Copyright

Copyright $\odot 2022$ The Author(s). Published by Wolters Kluwer Health, Inc. on behalf of the American Academy of Neurology.. All rights reserved. Online ISSN: 2332-7812.

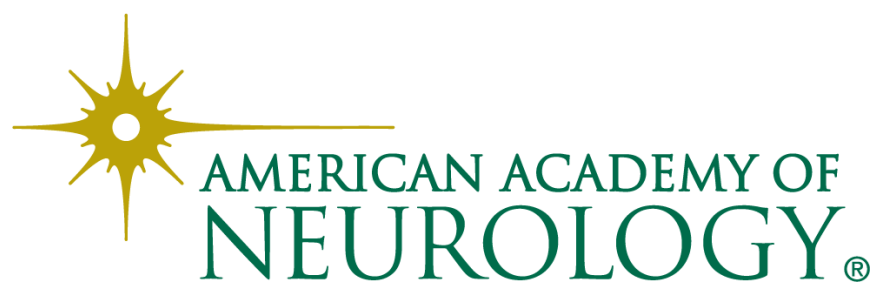




\section{Multimodal Investigation of Neuroinflammation in Aviremic Patients With HIV on Antiretroviral Therapy and HIV Elite Controllers}

Neurol Neuroimmunol Neuroinflamm 2022;9:e1175. doi:10.1212/NXI.0000000000001175

In the Article "Multimodal Investigation of Neuroinflammation in Aviremic Patients With HIV on Antiretroviral Therapy and HIV Elite Controllers" by Sari et al., 'the 20th author's name should be listed as "Marco L. Loggia." The article has been replaced by a corrected version. The authors regret the error.

\section{Reference}

1. Sari H, Galbusera R, Bonnier G, et al. Multimodal investigation of neuroinflammation in aviremic patients with HIV on antiretroviral therapy and HIV elite controllers. Neurol Neuroimmunol Neuroinflamm. 2022;9(2):e1144. 